\title{
A Three-Variable Model Predicts Short Survival in Patients With Newly Diagnosed Metastatic Renal Cell Carcinoma
}

\author{
Mohsan Ali Syed ${ }^{\mathrm{a}}$, Carsten Nieder ${ }^{\mathrm{a}, \mathrm{b}, \mathrm{c}}$
}

\begin{abstract}
Background: Patients with metastatic renal cell carcinoma (mRCC) have variable survival outcomes. When discussing management approaches and providing information to patients and caregivers, it is important to have realistic perspectives, especially if the expected prognosis is very unfavorable. In the present study, factors predicting this endpoint were analyzed.
\end{abstract}

Methods: Data from 60 patients treated in routine clinical practice were evaluated. Unfavorable prognosis was defined as death within approximately 3 months from diagnosis of mRCC (maximum 3.5 months). Baseline factors including laboratory values and management approach were compared between the groups with short and longer survival.

Results: A total of 48 patients $(80 \%)$ experienced $\geq 4$ months survival (4+MS) and 10 (16.7\%) experienced shorter survival (3MS). The others had short follow-up. Adverse prognostic factors that were significantly more frequent in the $3 \mathrm{MS}$ group were low hemoglobin, high lactate dehydrogenase and lack of systemic therapy. We used these three items to create a prognostic model: score $0=$ no adverse factors, score 1 = one adverse factor, score 2 = two adverse factors, score 3 $=$ three adverse factors. In the score 0 group, one out of 20 patients experienced $3 \mathrm{MS}(5 \%)$. In score 1 , two out of 21 patients belonged to the $3 \mathrm{MS}$ group $(9.5 \%)$. For score 2 , the corresponding figure was four out of 14 patients (29\%). In the score 3 group, three out of three patients experienced 3MS $(100 \%)(\mathrm{P}=0.0001)$.

Conclusions: A simple model with three prognostic factors predicted survival of patients with newly diagnosed mRCC. Additional validation in other databases is warranted.

Keywords: Kidney cancer; Metastatic renal cell carcinoma; Prognostic factors; Prognostic score; Systemic therapy

Manuscript accepted for publication December 08, 2016

aDepartment of Oncology and Palliative Medicine, Nordland Hospital, Bodo 8092, Norway

${ }^{b}$ Department of Clinical Medicine, Faculty of Health Sciences, UiT - The Arctic University of Norway, Tromso 9037, Norway

${ }^{\mathrm{c} C}$ Corresponding Author: Carsten Nieder, Department of Oncology and Palliative Medicine, Nordland Hospital, Bodo 8092, Norway.

Email: carsten.nieder@nlsh.no

doi: https://doi.org/10.14740/jocmr2839w

\section{Introduction}

In the National Cancer Registry of Norway (www.kreftregisteret.no), a total of 760 new cases of kidney cancer were registered in 2013 (533 in men and 227 in women) [1]. Kidney cancer occurred most often in the age group of $50-70$ years, and represented approximately $3 \%$ of the total diagnosed cancer cases. Over the last six decades, a gradually increasing incidence of kidney cancer has been seen in the country, especially among men [2]. The increase resembles international trends and is considered to be real even if one corrects for the increased use of computed tomography (CT) and ultrasound, which might detect small, asymptomatic tumors [3]. The prognosis is dependent on factors such as tumor size, grade and histological type [4]. Besides TNM classification, clinical factors including the general condition, symptom burden, cachexia and anemia are associated with the outcome. The presence of distant metastases (M1; stage IV disease or metastatic renal cell carcinoma (mRCC)) is a formidable clinical challenge [5], although long-term survival still can be achieved in a subgroup of patients, e.g. those with single brain metastasis $[6,7]$. Selecting the most appropriate local and systemic treatment approach is not trivial because the number of available options has increased tremendously [8]. In parallel, prognostic stratification models have been developed [9-15]. These models include multiple baseline parameters, e.g. pretreatment hemoglobin and lactate dehydrogenase $[13,15]$. When trying to select the best treatment option for an individual patient, the poor prognosis group is the most challenging one, because too aggressive approaches may result in serious side effects in these often frail patients. The purpose of our retrospective study was to identify prognostic factors for short survival in a contemporary cohort of patients with $\mathrm{mRCC}$ treated outside of clinical trials in accordance to national guidelines (available online, www.helsedirektoratet.no/retningslinjer/nasjonalt-handlingsprogram-med-retningslinjer-for-diagnostikk-behandlingog-oppfolging-av-pasienter-med-nyrecellekreft). Short survival was arbitrarily defined as death within approximately 3 months from diagnosis of mRCC.

\section{Patients and Methods}

Data from 60 consecutive patients from Nordland county in North Norway (a sparsely populated large rural area, main 
Table 1. Baseline Characteristics in 60 Patients With Metastatic Renal Cell Carcinoma

\begin{tabular}{|c|c|c|}
\hline Baseline characteristics & $\mathbf{n}$ & $\%$ \\
\hline No. of patients & 60 & 100 \\
\hline \multicolumn{3}{|l|}{ Gender } \\
\hline Male & 40 & 66.7 \\
\hline Female & 20 & 33.3 \\
\hline \multicolumn{3}{|l|}{ Age at metastatic disease } \\
\hline$<60$ years & 2 & 3.3 \\
\hline $60-69$ & 35 & 58.3 \\
\hline $70-79$ & 10 & 16.6 \\
\hline $80-89$ & 12 & 20.0 \\
\hline $90+$ & 1 & 1.7 \\
\hline \multicolumn{3}{|l|}{ Histology } \\
\hline Unknown & 8 & 13.3 \\
\hline Clear cell & 42 & 70.0 \\
\hline Papillary & 5 & 8.3 \\
\hline Sarcomatoid & 2 & 3.3 \\
\hline Chromofobic & 3 & 5.0 \\
\hline \multicolumn{3}{|l|}{ Nephrectomy } \\
\hline No & 21 & 35.0 \\
\hline Yes & 39 & 65.0 \\
\hline \multicolumn{3}{|l|}{ Distant metastases at first cancer diagnosis } \\
\hline Yes (synchronous) & 42 & 70.0 \\
\hline No (metachronous) & 18 & 30.0 \\
\hline \multicolumn{3}{|l|}{ Initial sites of distant metastases } \\
\hline Bone & 34 & 56.6 \\
\hline Lung & 29 & 48.3 \\
\hline Lymph node & 12 & 20.0 \\
\hline Liver & 10 & 16.6 \\
\hline Skin & 2 & 3.3 \\
\hline Brain & 16 & 26.6 \\
\hline \multicolumn{3}{|c|}{ Time interval from first cancer diagnosis to distant metastases } \\
\hline$<1$ year & 43 & 71.7 \\
\hline $1-5$ years & 10 & 16.7 \\
\hline$>5$ years & 7 & 11.7 \\
\hline \multicolumn{3}{|l|}{ Number of metastatic sites } \\
\hline 1, for example bone only & 16 & 26.7 \\
\hline 2 , for example brain and lung & 21 & 35.0 \\
\hline 3 or more & 23 & 38.3 \\
\hline \multicolumn{3}{|l|}{ Systemic treatment } \\
\hline Yes & 34 & 56.6 \\
\hline No & 26 & 43.3 \\
\hline \multicolumn{3}{|l|}{ Sunitinib vs. others } \\
\hline Sunitinib & 22 & 36.6 \\
\hline Pazopanib/temsirolimus/everolimus & 12 & 20.0 \\
\hline
\end{tabular}


Table 1. Baseline Characteristics in 60 Patients With Metastatic Renal Cell Carcinoma - (continued)

\begin{tabular}{|c|c|c|}
\hline Baseline characteristics & $\mathbf{n}$ & $\%$ \\
\hline \multicolumn{3}{|l|}{ ECOG performance status } \\
\hline $0-1$ & 18 & 30.0 \\
\hline 2 & 30 & 50.0 \\
\hline 3 & 12 & 20.0 \\
\hline \multicolumn{3}{|l|}{ Smoking } \\
\hline Yes & 34 & 56.7 \\
\hline No & 16 & 26.7 \\
\hline Unknown & 10 & 16.7 \\
\hline \multicolumn{3}{|l|}{ Comorbidity } \\
\hline Heart condition & 39 & 65.0 \\
\hline Diabetes mellitus & 7 & 11.7 \\
\hline Hypercholesterolemia & 4 & 6.7 \\
\hline Unknown & 10 & 16.7 \\
\hline \multicolumn{3}{|l|}{ Symptoms at first contact } \\
\hline Hematuria & 12 & 20.0 \\
\hline Bone pain/fracture & 16 & 26.7 \\
\hline Flank pain & 5 & 8.3 \\
\hline Weight loss & 14 & 23.3 \\
\hline Accidental finding & 13 & 21.7 \\
\hline \multicolumn{3}{|c|}{ Memorial Sloan Kettering Cancer Center (MSKCC) prognostic group } \\
\hline Good & 11 & 18.3 \\
\hline Intermediate & 28 & 46.7 \\
\hline Poor & 20 & 33.3 \\
\hline Unknown & 1 & 1.7 \\
\hline
\end{tabular}

city Bodo) with newly diagnosed mRCC were collected. All patients were managed in routine clinical practice under the guidance of the Department of Oncology and Palliative Medicine and the urology tumor board, which meets once weekly, at Nordland Hospital Bodo in the time period between 2000 and 2016. This oncology department is the only one in the county, a fact that assures complete clinical data in the electronic patient records (EPR), comparable to larger population-based cancer registries. Baseline characteristics and overall survival (OS) was extracted from the EPR, which cover information from all hospitals in North Norway. Patients were grouped according to survival, approximately 4 months or more and approximately 3 months or less (maximum 3.5 months). Baseline factors including patient characteristics, laboratory values (institutional upper limit of normal (ULN) and lower limit of normal (LLN)) and management approach were compared between the two groups with short and longer survival. The laboratory values were included because previous studies confirmed their prognostic relevance [9-17].

Synchronous distant metastases were defined as those cases in which lesions where observed prior to, together with or within 3 months after the diagnosis of RCC. The others were classified as metachronous metastases. We set this cut-off time point, since the first follow-up imaging studies occurred at 3 months in our institution. Patients were routinely examined by abdomino-pelvic and chest CT scans with intravenous contrast in order to identify potential metastases prior to nephrectomy. Following surgery, patients were followed primarily by CT scans and clinical examination, first within 3 months.

OS was defined as time period between newly diagnosed $\mathrm{mRCC}$ and the date of death, or censored on the day of the last follow-up visit.

\section{Statistical methods}

All analyses were performed with SPSS 22 (IBM, New York, USA). Actuarial survival was calculated with the KaplanMeier method, and compared between different groups with the log-rank test. Five patients were alive at the time of analysis with a median follow-up of 11 months. Associations between different variables of interest were assessed with the Chi-square or Fisher's exact probability test (two-tailed). A $\mathrm{P}$-value $\leq 0.05$ was considered statistically significant. As a retrospective quality of care analysis, no approval from the Regional Committee for Medical and Health Research Eth- 
Table 2. Pretreatment Blood Tests

\begin{tabular}{lll}
\hline Parameter & $\mathbf{n}$ & $\mathbf{\%}$ \\
\hline Low hemoglobin & 33 & 55.0 \\
Lactate dehydrogenase $>1.5$ time upper limit of normal & 4 & 6.7 \\
Lactate dehydrogenase $\geq 210$ U/L & 10 & 16.7 \\
Glasgow prognostic score 0 (normal C-reactive protein and albumin) & 11 & 18.3 \\
Glasgow prognostic score 1 & 36 & 60.0 \\
Glasgow prognostic score 2 (abnormal C-reactive protein and albumin) & 12 & 20.0 \\
Glasgow prognostic score unknown & 1 & 1.7 \\
\hline
\end{tabular}

ics (REK Nord) was necessary. Similarly no approval from the Norwegian Social Science Database (NSD) had to be obtained.

\section{Results}

Baseline characteristics are provided in Table 1. Mean age was 68 years (standard deviation 8.9 years; range 38 - 88 years). Forty-two patients $(70 \%)$ presented with mRCC already at first cancer diagnosis, the others with metachronous distant metastases. Clear cell histology was present in $70 \%$. Median hemoglobin was $12.0 \mathrm{~g} / \mathrm{dL}$ (range 8.6 - 16.6), as shown in Table 2. Therefore, low hemoglobin was defined as $<12.0 \mathrm{~g} / \mathrm{dL}$. Median lactate dehydrogenase (LDH) was $177 \mathrm{U} / \mathrm{L}$ (range 100 - 1,187). Abnormal LDH $\geq 210 \mathrm{U} / \mathrm{L}$ (ULN) was present in 10 patients (16.7\%). According to the Memorial Sloan Kettering Cancer Center (MSKCC) model [18], 11 patients (18\%) belonged to the good prognostic group, while 28 and 20 patients $(47 \%$ and $33 \%)$ had intermediate and poor prognostic features, respectively. Thirty-four patients $(57 \%)$ received systemic treatment. The most common first-line drug was sunitinib. The other patients were managed with active surveillance, surgery, radiotherapy or best supportive care.

Median survival was 13.2 months with a 2-year survival rate of $40 \%$ (Fig. 1). A total of 48 patients (80\%) experienced $\geq 4$ months survival (4+MS) and 10 (17\%) experienced shorter survival (3MS). The others were alive with short follow-up $<3$ months. All baseline parameters were evaluated in order to find those predicting shorter survival (3MS). As shown in Table 3, low hemoglobin $<12.0 \mathrm{~g} / \mathrm{dL}$, high $\mathrm{LDH} \geq 210 \mathrm{U} / \mathrm{L}$ and lack of systemic therapy were significantly associated

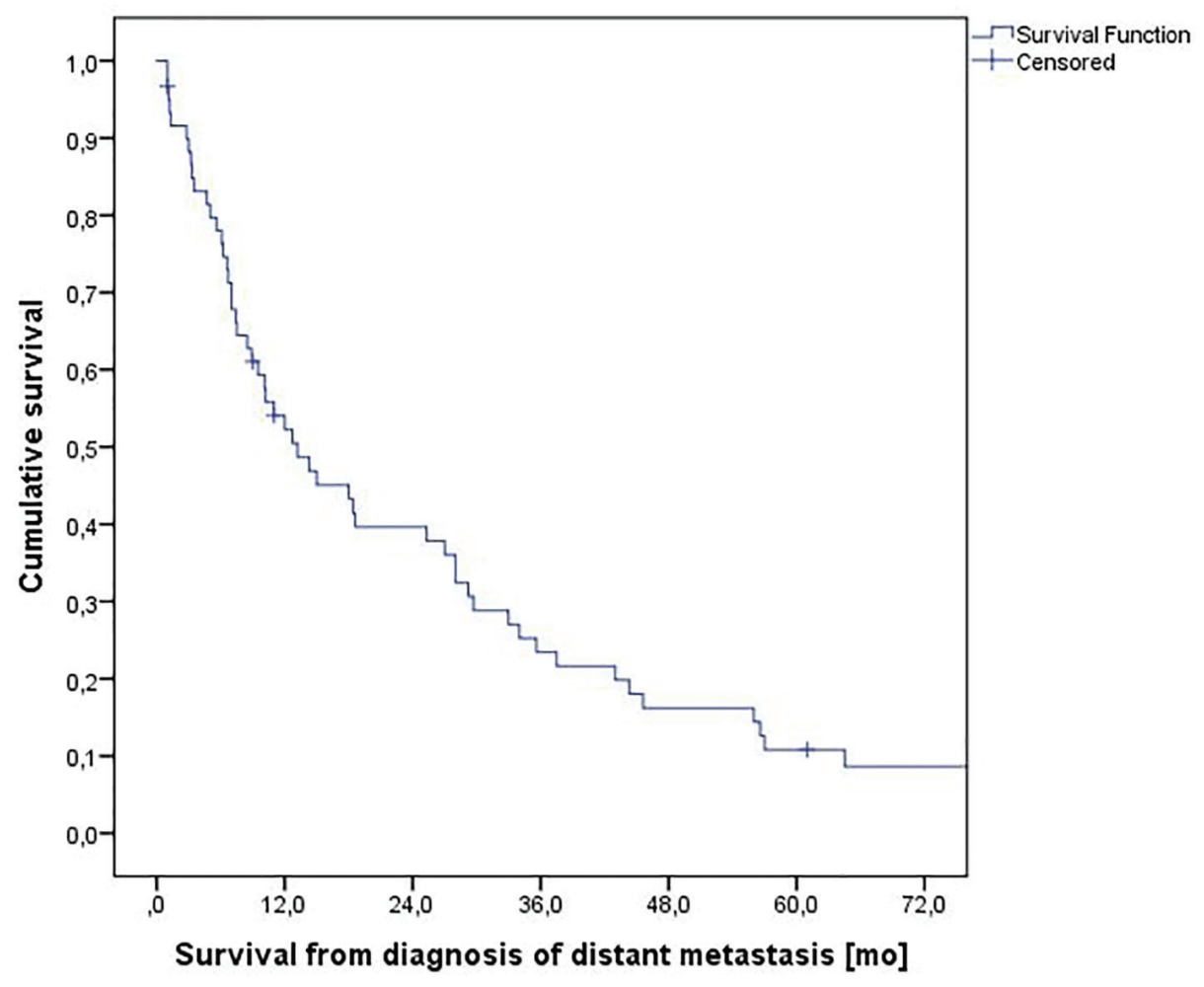

Figure 1. Actuarial overall survival from diagnosis of metastatic renal cell carcinoma, $n=60$. 
Table 3. Association Between Baseline Parameters and Survival Outcome (Parameters With P-Value $>0.3$ Not Shown)

\begin{tabular}{lll}
\hline Parameter & Patients who died within about 3 months (\%) & P-value \\
\hline Systemic treatment & 5.9 & 32.0 \\
No systemic treatment & 20.5 & 0.008 \\
Interval between first cancer diagnosis and distant metastases $<1$ year & 6.7 \\
Longer interval & 50.0 \\
Skin metastases & 14.5 \\
No skin metastases & 13.2 \\
Nephrectomy & 25.0 \\
No nephrectomy & 28.0 \\
Hemoglobin $<12 \mathrm{~g} / \mathrm{dL}$ & 9.1 \\
Hemoglobin $\geq 12 \mathrm{~g} / \mathrm{dL}$ & 44.4 \\
Lactate dehydrogenase $\geq 210 \mathrm{U} / \mathrm{L}$ & 12.0 \\
Lactate dehydrogenase $<210 \mathrm{U} / \mathrm{L}$ & 0.27 \\
\hline
\end{tabular}

with $3 \mathrm{MS}$. Trends were seen for skin metastases, lack of nephrectomy and interval between first cancer diagnosis and distant metastases $<1$ year. No trends emerged for all other parameters including MSKCC model, Glasgow prognostic score (GPS) [19], performance status and number of involved organs.

We used the three items with significant P-value to create a prognostic model. Score 0 means no adverse factors, score 1 means one adverse factor, score 2 means two adverse factors, and score 3 means three adverse factors. In the score 0 group, one out 20 patients experienced $3 \mathrm{MS}(5 \%)$. In score 1 , two out of 21 patients belonged to the 3MS group (9.5\%). For score 2 , the corresponding figure was four out of 14 patients $(29 \%)$. In the score 3 group, three out of three patients experienced $3 \mathrm{MS}$ $(100 \%)(\mathrm{P}=0.0001)$. A survival plot based on these adverse factors is shown in Figure 2.

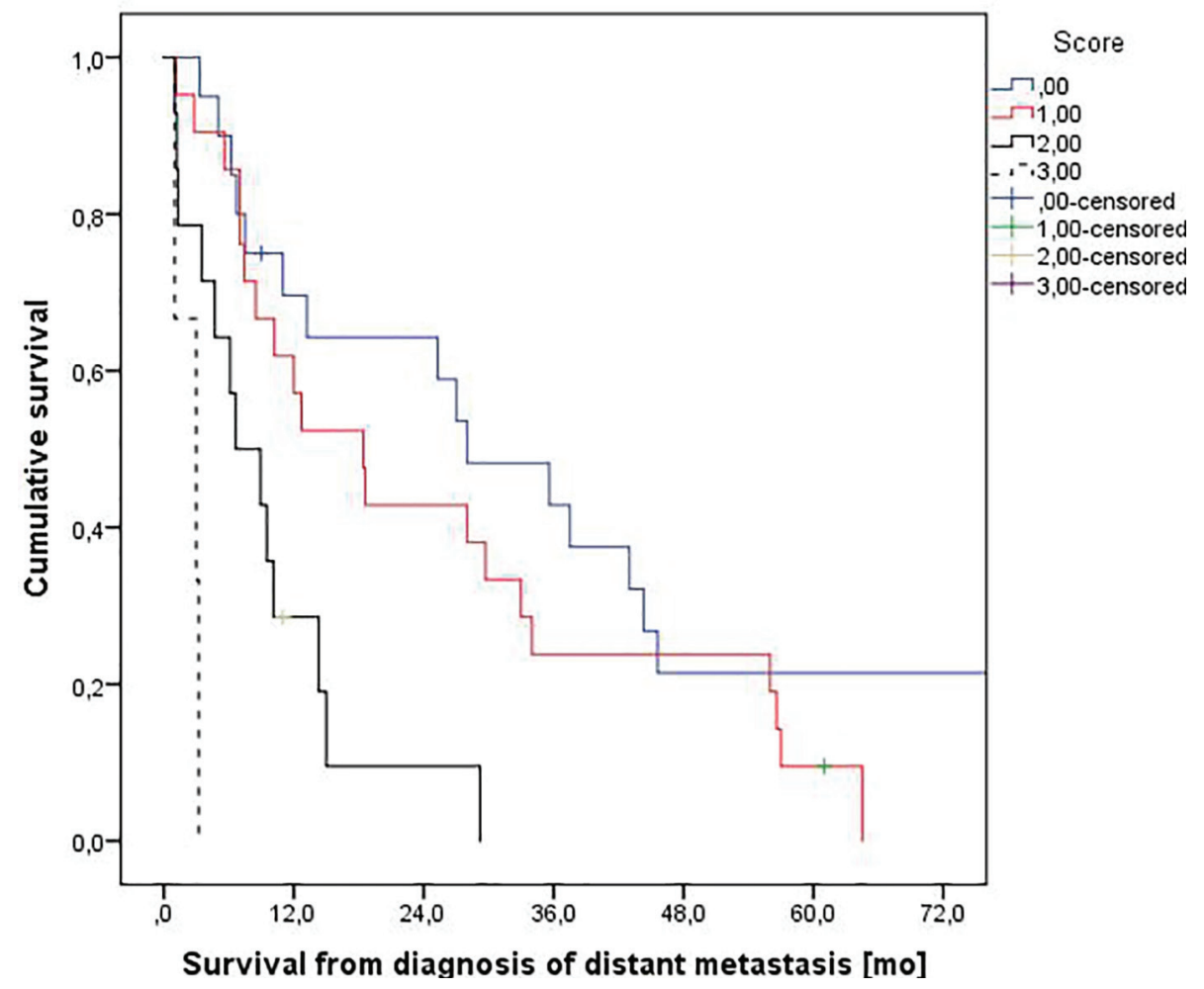

Figure 2. Actuarial overall survival stratified by a three-variable prognostic score. Median survival was 28.0, 18.4, 6.6 and 3.0 months, respectively $(P=0.0001$, log-rank test pooled over all strata). Numbers of patients in the four groups were $20,21,14$, and 3. 


\section{Discussion}

In this retrospective analysis, we assessed prognostic factors in a series of 60 patients treated in routine clinical practice in a rural part of Norway. Most patients presented with synchronous distant metastases at the time of diagnosis of clinically symptomatic clear cell cancer. Adverse prognostic factors derived from well-known models were often present, e.g., unfavorable MSKCC score in 33\% and ECOG performance status 2 or 3 in $50 \%$ and $20 \%$, respectively. Nevertheless, the majority was treated with nephrectomy and systemic therapy. We focused on short survival, because identification of patients with extremely poor prognosis is important, both for the patients, their families and caregivers, oncologists and specialists in palliative care [20]. In the era of precision oncology and increasing costs of oncology care, assigning the right treatment for the right patient does not only mean identifying appropriate targets for systemic therapy [21,22], but also limiting the risk of overtreatment and toxicity in the final weeks of life. We propose a three-variable model based on factors predicting short survival (3MS), an endpoint that was associated with low hemoglobin $<12.0 \mathrm{~g} / \mathrm{dL}$, high $\mathrm{LDH} \geq 210 \mathrm{U} / \mathrm{L}$ and lack of systemic therapy.

Certain limitations should be taken into consideration when interpreting our study. Firstly, we collected data from a small group of patients, which resulted in limited statistical power. For example, the presence of skin metastases might have turned out as statistically significant prognosticator in a larger study. Secondly, treatment was heterogeneous and included, for example, systemic therapy with sunitinib, pazopanib, temsirolimus and everolimus, as well as palliative radiotherapy alone. The decision not to treat systemically reflects complex judgments, taking into account patient preference, frailty, comorbidity, etc. However, absence of systemic therapy was on its own not sufficient to predict short survival (68\% of patients experienced $4+\mathrm{MS}$ ). Thirdly, patients with non-clear cell histology were also included. Even if characteristics such as histology and choice of drug were not associated with prognosis, larger confirmatory studies should be attempted in the future. When defining 3MS we included patients who survived the 3-month benchmark by $1-2$ weeks in order to increase the number of statistical events. Survival between 3.5 and 4 months was not observed; therefore the comparator was named $4+\mathrm{MS}$. We believe it is a strength of our study that unselected real world patients were analyzed, who were not required to fulfill all the inclusion and exclusion criteria that are typical for prospective studies. In addition, the publicly funded Norwegian health care system provides equal access to care without financial barriers, and also national treatment guidelines.

Unexpectedly, the endpoint of 3MS was not significantly associated with performance status, number of metastatic organ sites, Glasgow prognostic score and MSKCC score. Not even trends emerged for these parameters. When comparing the complete range of OS (Kaplan-Meier curves), different results can be observed $[9,11,18,19]$. In the previous literature, general analyses of OS with log-rank tests and Cox proportional hazard models were more common than analyses of a particular cut-off for short survival [16, 23, 24].

The MSKCC risk system stratifies patients with $\mathrm{mRCC}$ into poor-, intermediate- and favorable-risk categories based on the number of adverse clinical and laboratory parameters present [18]. Poor prognostic factors include a Karnofsky performance status (KPS) of less than 80 , time from diagnosis to treatment less than 12 months (initially prior nephrectomy was included), serum LDH more than 1.5 times the ULN, corrected serum calcium $>10.0 \mathrm{mg} / \mathrm{dL}$ and hemoglobin less than the LLN. Patients in the favorable-risk group have no poor prognostic factors, those in the intermediate-risk category have one or two adverse prognostic factors, and patients with poor-risk RCCs have more than two poor prognostic factors. This widely known model was not developed with the aim of predicting the endpoint of our study, i.e. 3MS. It is therefore not surprising to see that the MSKCC risk system cannot be recommended for this particular purpose.

The Heng or International Metastatic Renal Cell Carcinoma Database Consortium model stratifies patients into three risk categories according to their number of risk factors: favorable-risk (no risk factors), intermediate-risk (one or two risk factors), and high-risk (more than two risk factors) [12, 13]. It includes anemia, thrombocytosis, neutrophilia, KPS $<$ $80,<1$ year from diagnosis to first-line targeted therapy and hypercalcemia. Since not all these parameters were routinely assessed in our patients and statistical power would have been worse with even smaller sample size, we refrained from assigning this model, whose purpose is to predict prognosis in general rather than 3MS, similar to the MSKCC risk system.

We compared our results with a larger retrospective Canadian study, which included data obtained from the medical records of all patients diagnosed with $\mathrm{mRCC}$ at two Canadian centers, from July 2007 until December 2011 [25]. The authors reviewed data from 120 patients, and included all 89 patients who received at least one cycle of active treatment. The remaining 31 patients did not receive treatment and were excluded from the analysis. Their final multivariate model included three different risk factors: hemoglobin, prior nephrectomy, and time from diagnosis to treatment. Patients in the high-risk group (two or three risk factors) had a median survival of 5.9 months, while those in the intermediate-risk group (one risk factor) had a median survival of 16.2 months, and those in the low-risk group (no risk factors) had a median survival of 50.6 months. They concluded that shorter survival times were associated with hemoglobin below the LLN, absence of prior nephrectomy, and initiation of treatment within 1 year of diagnosis. Interestingly, hemoglobin is included as a prognostic factor in all the studies discussed here $[9,11$, $12,24]$. The Canadian high-risk group had a median survival of 5.9 months [25], which in our opinion qualifies for active treatment as opposed to best supportive care. However, patients succumbing shortly after diagnosis are more likely to experience disadvantages from therapy, including toxicity, than positive effects and might therefore be considered for immediate palliative care. We arbitrarily defined short survival as 3 months; however, other definitions could also be applied. Even if our study generates hypotheses only, it provides stimuli for larger analyses, which are urgently needed to better understand the optimal approach towards patients with 
very unfavorable survival.

\section{Conclusion}

The retrospective analysis of survival data in unselected patients may be of value for those individuals that are underrepresented in prospective clinical studies, such as poor-risk patients (33\% of our population). A simple model with three prognostic factors predicted the likelihood of 3MS in patients with newly diagnosed $\mathrm{mRCC}$. Additional validation in other databases is warranted.

\section{Grant}

This research did not receive any specific grant from funding agencies in the public, commercial, or not-for-profit sectors.

\section{Conflicts of Interest}

None.

\section{References}

1. Cancer in Norway 2013. Cancer Registry of Norway, Institute of Population-based Research. Oslo, Norway. http://www.kreftregisteret.no.

2. Lindblad P. Epidemiology of renal cell carcinoma. Scand J Surg. 2004;93(2):88-96.

3. Siegel R, Ma J, Zou Z, Jemal A. Cancer statistics, 2014. CA Cancer J Clin. 2014;64(1):9-29.

4. Sun M, Shariat SF, Cheng C, Ficarra V, Murai M, Oudard S, Pantuck AJ, et al. Prognostic factors and predictive models in renal cell carcinoma: a contemporary review. Eur Urol. 2011;60(4):644-661.

5. Alt AL, Boorjian SA, Lohse CM, Costello BA, Leibovich BC, Blute ML. Survival after complete surgical resection of multiple metastases from renal cell carcinoma. Cancer. 2011;117(13):2873-2882.

6. Nieder C, Spanne O, Nordoy T, Dalhaug A. Treatment of brain metastases from renal cell cancer. Urol Oncol. 2011;29(4):405-410.

7. Bastos DA, Molina AM, Hatzoglou V, Jia X, Velasco S, Patil S, Voss MH, et al. Safety and efficacy of targeted therapy for renal cell carcinoma with brain metastasis. Clin Genitourin Cancer. 2015;13(1):59-66.

8. Alimohamed N, Lee JL, Srinivas S, Bjarnason GA, Knox JJ, Mackenzie MJ, Wood L, et al. A populationbased overview of sequences of targeted therapy in metastatic renal cell carcinoma. Clin Genitourin Cancer. 2014;12(4):e127-131.

9. Motzer RJ, Mazumdar M, Bacik J, Berg W, Amsterdam A, Ferrara J. Survival and prognostic stratification of 670 patients with advanced renal cell carcinoma. J Clin Oncol. 1999; 17(8):2530-2540.
10. Leibovich BC, Cheville JC, Lohse CM, Zincke H, Frank I, Kwon ED, Merchan JR, et al. A scoring algorithm to predict survival for patients with metastatic clear cell renal cell carcinoma: a stratification tool for prospective clinical trials. J Urol. 2005;174(5):1759-1763; discussion 1763.

11. Bamias A, Karadimou A, Lampaki S, Lainakis G, Malettou L, Timotheadou E, Papazisis K, et al. Prognostic stratification of patients with advanced renal cell carcinoma treated with sunitinib: comparison with the Memorial Sloan-Kettering prognostic factors model. BMC Cancer. 2010;10:45.

12. Heng DY, Xie W, Regan MM, Warren MA, Golshayan AR, Sahi C, Eigl BJ, et al. Prognostic factors for overall survival in patients with metastatic renal cell carcinoma treated with vascular endothelial growth factor-targeted agents: results from a large, multicenter study. J Clin Oncol. 2009;27(34):5794-5799.

13. Heng DY, Xie W, Regan MM, Harshman LC, Bjarnason GA, Vaishampayan UN, Mackenzie M, et al. External validation and comparison with other models of the International Metastatic Renal-Cell Carcinoma Database Consortium prognostic model: a population-based study. Lancet Oncol. 2013;14(2):141-148.

14. Fay AP, Xie WL, Lee JL, Harshman LC, Bjarnason GA, Knox JJ, Ernst S, et al. Characteristics of long-term and short-term survivors of metastatic renal cell carcinoma treated with targeted therapies: results from the International mRCC Database Consortium. Clin Genitourin Cancer. 2015;13(2):150-155.

15. Manola J, Royston P, Elson P, McCormack JB, Mazumdar M, Negrier S, Escudier B, et al. Prognostic model for survival in patients with metastatic renal cell carcinoma: results from the international kidney cancer working group. Clin Cancer Res. 2011;17(16):5443-5450.

16. Donskov F, von der Maase H. Impact of immune parameters on long-term survival in metastatic renal cell carcinoma. J Clin Oncol. 2006;24(13):1997-2005.

17. Motzer RJ, Escudier B, Bukowski R, Rini BI, Hutson TE, Barrios CH, Lin X, et al. Prognostic factors for survival in 1059 patients treated with sunitinib for metastatic renal cell carcinoma. Br J Cancer. 2013;108(12):24702477.

18. Motzer RJ, Bacik J, Mazumdar M. Prognostic factors for survival of patients with stage IV renal cell carcinoma: memorial sloan-kettering cancer center experience. Clin Cancer Res. 2004;10(18 Pt 2):6302S-6303S.

19. Ramsey S, Lamb GW, Aitchison M, Graham J, McMillan DC. Evaluation of an inflammation-based prognostic score in patients with metastatic renal cancer. Cancer. 2007;109(2):205-212.

20. Day D, Kanjanapan Y, Kwan E, Yip D, Lawrentschuk N, Andrews M, Davis ID, et al. Patterns of care for metastatic renal cell carcinoma in Australia. BJU Int. 2015;116(Suppl 3):36-41.

21. Rothermundt C, Bailey A, Cerbone L, Eisen T, Escudier B, Gillessen S, Grunwald V, et al. Algorithms in the FirstLine Treatment of Metastatic Clear Cell Renal Cell Carcinoma - Analysis Using Diagnostic Nodes. Oncologist. 
2015;20(9):1028-1035.

22. Ciccarese C, Brunelli M, Montironi R, Fiorentino M, Iacovelli R, Heng D, Tortora G, et al. The prospect of precision therapy for renal cell carcinoma. Cancer Treat Rev. 2016;49:37-44.

23. Heng DY, Wells JC, Rini BI, Beuselinck B, Lee JL, Knox JJ, Bjarnason GA, et al. Cytoreductive nephrectomy in patients with synchronous metastases from renal cell carcinoma: results from the International Metastatic Renal Cell Carcinoma Database Consortium. Eur Urol.
2014;66(4):704-710.

24. Mathieu R, Pignot G, Ingles A, Crepel M, Bigot P, Bernhard JC, Joly F, et al. Nephrectomy improves overall survival in patients with metastatic renal cell carcinoma in cases of favorable MSKCC or ECOG prognostic features. Urol Oncol. 2015;33(339):e9-e15.

25. Assi HI, Patenaude F, Toumishey E, Ross L, Abdelsalam M, Reiman T. A simple prognostic model for overall survival in metastatic renal cell carcinoma. Can Urol Assoc J. 2016;10(3-4):113-119. 